\title{
Electrical stimulation therapy of the lower esophageal sphincter in GERD patients - a prospective single-center study
}

\author{
Matthias Paireder · Ivan Kristo · Milena Nikolic · Gerd Jomrich · Johannes Steindl · Erwin Rieder · Reza Asari • \\ Sebastian F. Schoppmann
}

Received: 29 September 2020 / Accepted: 9 October 2020 / Published online: 4 November 2020 (C) The Author(s) 2020

\begin{abstract}
Summary
Background Electrical stimulation therapy (EST) of the lower esophageal sphincter (LES) for gastro esophageal reflux disease (GERD) treatment increases LES pressure through chronic stimulation, with a low risk for gastrointestinal side effects and preservation of hiatal anatomy. The aim of this study was to evaluate the efficacy and safety of this novel technique in a high-output specialized reflux center.

Methods This is a prospective single-center study including GERD patients indicated for anti-reflux therapy who consented to undergo LES-EST. Patients underwent prospective scheduled follow-up visits including interrogation of the stimulation device, clinical examination, and assessment of health-related quality of life (HRQL).

Results Within a 4-year period, 37 LES-EST implantations were performed. The majority of patients were male (54.1\%), mean BMI was 25.8 (SD 4.4), and mean age was 54.0 (SD 15.8). The median GERD HRQL composite score was 41 (IQR 21-49). Median total \% of $\mathrm{pH}<4$ was 10.1 (IQR 4.4-17.3). Six (16.2\%) individuals underwent explantation of the entire system (IPG and leads) due to technical defect $(n=4)$ or failure of therapy $(n=2)$. HRQL score improved from 41 (IQR $21-49$ ) to 8.50 (IQR $4.25-20.5, p<0.001$ ) and 9 (23.7\%) patients were on at least occasional PPI treatment.
\end{abstract}

M. Paireder, MD · I. Kristo, MD · M. Nikolic, MD .

G. Jomrich, MD · J. Steindl · E. Rieder, MD · R. Asari, MD •

S. F. Schoppmann, MD, F.A.C.S. ( $₫)$

Department of Surgery, Upper-GI-Service, Comprehensive Cancer Center GET-Unit, Medical University of Vienna, Spitalgasse 23, 1090 Vienna, Austria

sebastian.schoppmann@meduniwien.ac.at

J. Steindl

Surgical Department, Medical University of Graz, Graz, Austria
Conclusion Due to the low rate of GI side effects and its minimal invasive character preserving the hiatal anatomy, this novel technique might find its place in anti-reflux surgery. However, the considerably high rate of device dysfunction needs further investigation.

Keywords Electrical stimulation therapy - Health related quality of life score - Lower esophageal sphincter · Antireflux surgery · Gastrointestinal side effects

\section{Main novel aspects}

- This study presents outcomes after electrical stimulation therapy of the lower esophageal sphincter.

- This is the largest single-center study to date, which demonstrates safety and efficacy of LES-EST.

- This is the first study presenting comprehensive information of explanation of the EndoStim device.

\section{Introduction}

Gastroesophageal reflux disease (GERD) is an underestimated burden of health loss with a prevalence of up to $27.8 \%$ in Western countries [1]. A recent systematic analysis using data of the Global Burden of Disease Study 2017 revealed that GERD burden is increasing as a result of ageing and population growth [2]. The pathogenic mechanism of GERD is described as simple [3]: if the competence of the lower esophageal high-pressure zone fails, acidic gastric content will flow back into the esophagus [4].

A novel technique, initially described in an experimental canine model in 1968, utilizes electrical stimulation (EST) of the lower esophageal sphincter (LES), aiming to increase LES pressure $[5,6]$. Furthermore, it was hypothesized that improving LES pressure without significantly altering anatomical structures may 


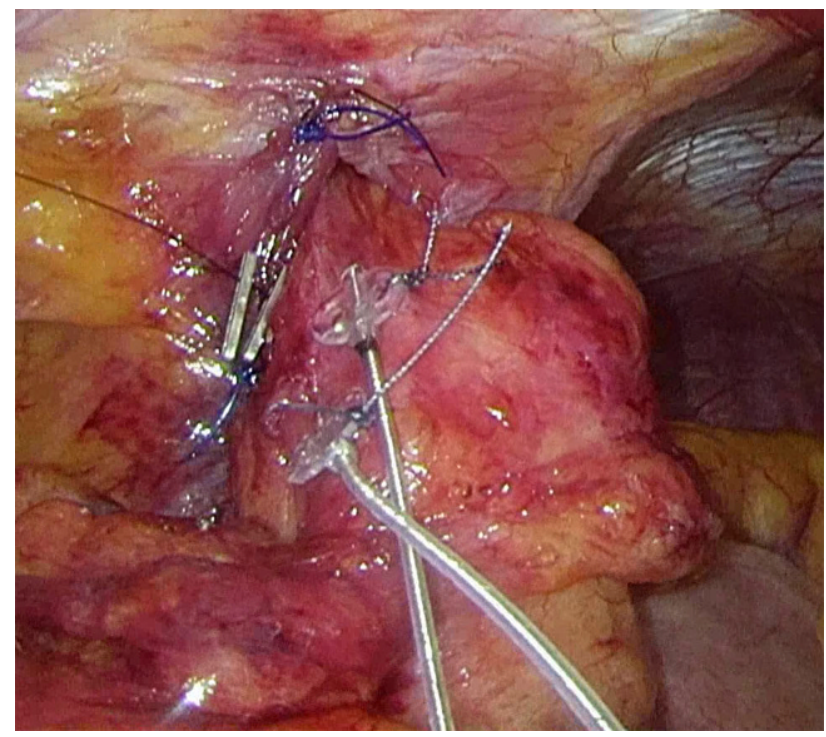

Fig. 1 Intraoperative site after implantation of the stitch electrodes and hiatoplastic

result in a very low profile of side effects [7]. An open-label trial endorsed promising early results [8, 9]. The results were confirmed by an interim analysis of a multicenter trial [10]. Interestingly, this trial positively evaluated the safety and efficacy of LESEST in patients with an incomplete response to proton pump inhibitors (PPI). Furthermore LES-EST was demonstrated to be a promising option for patients presenting a severe esophageal motility disorder such as ineffective esophageal motility (IEM) by preventing postoperative dysphagia [11]. In a pig model, LESEST was discussed to be effective after per-oral endoscopic myotomy (POEM) of the distal esophagus [12]. In a recent case report of a patient with severe GERD following POEM, first results showed a positive effect on GERD symptoms after LES-EST implantation [13].

The aim of this study was to evaluate the efficacy and safety of this novel technique in a high-output specialized reflux center.

\section{Materials and methods}

\section{Study protocol}

This is a prospective, open-label, single-center study. All candidates were referred to our tertiary specialized center for evaluation of the possible indication for anti-reflux surgery. If surgery was indicated, patients were screened for eligibility to undergo electrical LES stimulation.

The aim of this study was to assess the safety and efficacy of LES-EST, including medical morbidity associated with the device and/or implantation procedure as well as the assessment of postoperative side effects such as dysphagia, bloating, or inability to belch or vomit.
All patients meeting the indication for anti-reflux surgery were eligible for the study. All patients gave their informed consent prior to their inclusion in the study.

Preoperative workup included upper GI endoscopy as well as esophageal function testing including high-resolution impedance manometry (InSIGHT Ultima $^{\circledR}$, Sandhill Scientific Inc., USA) and 24-hour impedance/pH reflux monitoring $\left(\mathrm{ZepHr}^{\circledR}\right.$, Sandhill Scientific Inc., USA).

Follow-up was performed 1, 6, 12, and 24 months after surgery. This consisted of physical examination as well as interrogation of the device and health-related quality of life (HRQL) assessment with standardized questionnaires (GERD-HRQL for heartburn and regurgitation) [14]. Dysphagia was graded from 0 to 4 according to the standardized classification used by Mellow and Pinkas [15].

The study was approved by the ethics committee (EK 1149/2014) of the Medical University of Vienna. All patient data were pseudonymized and also included in an international patient registry (NCT02441400).

\section{Implantation technique}

Device implantation was performed as described previously [10]. In brief, with the patient in the antiTrendelenburg position, minimal dissection of the abdominal and lower mediastinal esophagus was performed using an ultrasound-based energy device. In the case of hiatal hernia, complete mobilization of the distal esophagus and posterior hiatal repair was performed. The two stimulation electrodes were placed under endoscopic control at the anterior side of the EGJ approximately $1.5 \mathrm{~cm}$ apart and were fixed with 3/0 multifilament, non-absorbable thread, which is applied at least on one side of each silicone butterfly ([8]; Fig. 1). A contrast swallow was performed at day one after surgery as well as an abdominal x-ray for documentation of the position of the lead and electrodes. Patients were encouraged to take in a soft diet for 4 days.

\section{Statistical analysis}

IBM SPSS Statistics, version 21.0 (IBM Corp., Armonk, NY, USA) was used for statistical analysis.

All variables are depicted as median and interquartile range (IQR) or 95\% confidence intervals (CIs), or mean with standard deviation (SD). Ineffective esophageal motility (IEM) was defined as distal contractile integral (DCI; unit: amplitude-duration . length $-\mathrm{mmHg} \cdot \mathrm{s} \cdot \mathrm{cm}$ ) below $450 \mathrm{mmHg} \cdot \mathrm{s} \cdot \mathrm{cm}$ in $\geq 5$ of out 10 swallows. Operating time was defined as the period between placement of the last trocar and removal of the first trocar. Differences in GERD healthrelated quality of life (HRQL) scores and electrical impedance before and after treatment were com- 
Fig. 2 EndoStim Generation II device (EndoStim B.V., Den Haag, The Netherlands)

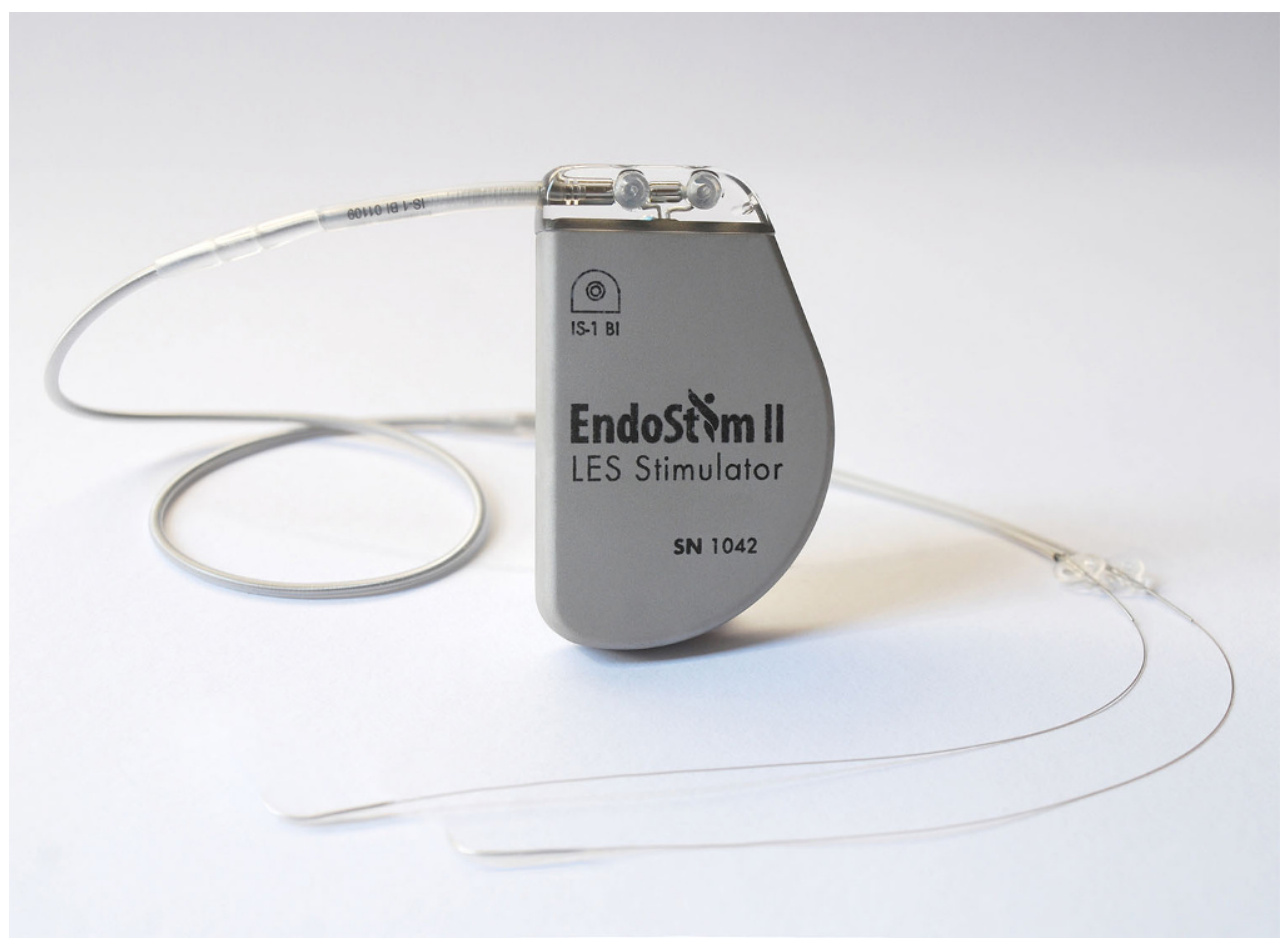

pared with paired $t$-test due to normal distribution. $P$-values $<0.05$ were considered significant. Graphing was performed with GraphPad Prism (version 7.0c, GraphPad Software, Inc., La Jolla, CA, USA).

\section{Results}

\section{Patients}

Between 2014 and 2019, 37 implantations of LESEST were performed. Gender distribution was almost equal $(54.1 \%$ male patients). Weight distribution was $56.8 \%$ BMI $<25 \mathrm{~kg} / \mathrm{m}^{2}, 27 \% \mathrm{BMI} \geq 25 \mathrm{~kg} / \mathrm{m}^{2}$ and $<30 \mathrm{~kg} / \mathrm{m}^{2}$, and $16.2 \% \mathrm{BMI} \geq 30 \mathrm{~kg} / \mathrm{m}^{2}$. Mean age was 54 years (SD 15.8). Median follow-up was 18.6 months (IQR 10.85-25.15). Thirty-one (83.8\%) patients reported PPI intake on a regular basis before surgery. Twenty-nine $(78.4 \%)$ patients reported typical GERD symptoms, whereas 16 (43.2\%) reported atypical symptoms. The most frequently mentioned symptom was heartburn $(86.5 \%)$. The median GERD HRQL composite score was 41 (IQR 21-49). Median total \% of $\mathrm{pH}<4$ was 10.1 (IQR 4.4-17.3), median number of reflux events was 79 (IQR 48.2-104.3), whereas median end expiratory pressure of the LES was $17.0 \mathrm{mmHg}$ (IQR 12.0-25.4). Twenty-five (68\%) of the patients fulfilled the criteria of ineffective esophageal motility showing a median DCI of 360 (IQR 56-734) $\mathrm{mmHg} \cdot \mathrm{s} \cdot \mathrm{cm}$ (also see Tables 1 and 2).

\section{Surgery}

All patients underwent laparoscopic implantation of the EndoStim ${ }^{\circledR}$ device (Fig. 2). Intraoperative en- doscopy did not show any case of perforation during lead implantation. In $23(62.2 \%)$ patients an additional hiatal repair was performed. Median operating time was $55 \mathrm{~min}$ (IQR 41.4-70.3). One patient had to undergo a redo surgery due to failure of the stimulation system (lead breakage) after 284 days. Eventually, $4(10.8 \%)$ patients, including the patient with redo surgery after lead breakage, underwent explantation of the EST device due to technical issues. Another two patients had insufficient symptom control and the EST device was removed. These 6 (16.2\%) individuals underwent explantation of the entire system (IPG and leads) and successful conversion to Nissen fundoplication.

Six $(15.8 \%)$ patients had had previous foregut surgery. One patient had four previous fundoplications, one patient three previous fundoplications, two patients had one previous fundoplication, one patient underwent a preceding POEM procedure, and one patient had a resection of the fundus due to perforation during redo fundoplication. All those patients also successfully underwent the implantation procedure of LES-EST.

\section{Follow-up}

No patients reported any clinical signs of dysphagia or gastrointestinal side effects such as bloating or inability to belch or vomit, neither in the early postoperative phase nor in long-term follow up. One patient suffered from subcutaneous emphysema, which resolved without intervention. Contrast swallow on postoperative day one did not show any adverse events such as 
Table 1 Demographical and baseline characteristics

\begin{tabular}{|c|c|c|c|}
\hline \multicolumn{2}{|c|}{ Characteristic } & $N(\%)$ & $\begin{array}{l}\text { Mean }(S D)^{a} / \text { median } \\
(\text { IQR) })^{b}\end{array}$ \\
\hline \multicolumn{2}{|l|}{ Age, years ${ }^{b}$} & 37 & $54.0(15.8)^{\mathrm{a}}$ \\
\hline \multicolumn{2}{|c|}{ Body mass index (BMI) ${ }^{b}$} & 37 & $25.8(4.4)^{\mathrm{a}}$ \\
\hline \multirow[t]{2}{*}{ Gender } & Male & $20(54.1)$ & - \\
\hline & Female & $17(45.9)$ & - \\
\hline \multirow[t]{3}{*}{ BMI class } & Normal $(<25)$ & $21(56.8)$ & - \\
\hline & $\begin{array}{l}\text { Overweight ( } \geq 25 \text { and } \\
<30 \text { ) }\end{array}$ & $10(27.0)$ & - \\
\hline & Obese $(\geq 30)$ & 6 (16.2) & - \\
\hline \multicolumn{2}{|c|}{ Patients using daily PPI } & $31(83.8)$ & - \\
\hline \multicolumn{2}{|c|}{ Typical GERD symptoms } & $29(78.4)$ & - \\
\hline \multicolumn{2}{|c|}{ Atypical GERD symptoms } & 16 (43.2) & - \\
\hline \multicolumn{2}{|c|}{ Heartburn } & $32(86.5)$ & - \\
\hline \multicolumn{2}{|c|}{ Regurgitation } & $28(75.7)$ & - \\
\hline \multicolumn{2}{|c|}{ Chronic cough } & $11(29.7)$ & - \\
\hline \multicolumn{2}{|c|}{ Stomach pain } & $6(16.2)$ & - \\
\hline \multicolumn{2}{|c|}{ Retrosternal pain } & 6 (16.2) & - \\
\hline \multicolumn{2}{|c|}{ Difficulty swallowing } & 7 (18.9) & - \\
\hline \multirow{3}{*}{$\begin{array}{l}\text { GERD-HRQL } \\
\text { score }\end{array}$} & Heartburn (IQR) & - & $21(13-28)^{b}$ \\
\hline & Regurgitation (IQR) & - & $18(11-23.5)^{b}$ \\
\hline & Total (IQR) & - & $41(21-49)^{b}$ \\
\hline \multicolumn{4}{|c|}{$\begin{array}{l}\text { Values in parentheses are percentages unless indicated otherwise } \\
P P I \text { proton pump inhibitors, GERD gastroesophageal reflux disease, } \\
H R Q L \text { health-related quality of life, BMI body mass index } \\
\text { aValues are mean (SD standard deviation) } \\
\text { bValues are median (IQR interquartile range) }\end{array}$} \\
\hline
\end{tabular}

obstruction or perforation. Median time of hospital stay was 2 days (IQR 2-2.5; Table 3).

Two years after surgery the composite HRQL score improved from 41 (IQR 21-49) to 8.50 (IQR 4.25-20.5, $p<0.001$ ). The symptoms heartburn and regurgitation also significantly improved from 21 (IQR 13-28) to 5 $(1.5-12.5, p<0.001)$, and $18(11-23.5)$ to 3 (IQR 1.5-5.5, $p<0.001$ ), respectively (Figs. 3, 4 and 5).

One year after surgery, $9(23.7 \%)$ patients were on at least occasional PPI treatment. Electrical impedance rose from median 320 (IQR 291-352) during implantation to median 526 (IQR 507-618) at 1-year follow up, $p<0.0001$. Dysfunction of the device in the 4 patients mentioned above was noticed due to impedance out of range. Two (5.4\%) patients developed mild thoracic sensations during the stimulation period. This problem could be solved by reduction of the stimulation amplitude to $2.5 \mathrm{mAmp}$.

\section{Discussion}

According to the current literature, this report is the largest prospective single-center series of LES-EST in GERD patients. We provide evidence that LES-EST can significantly reduce bothersome GERD symptoms
Table 2 Preoperative esophageal functional testing

\begin{tabular}{l|l|l|}
\hline Esophageal functional testing & $n=37$ & \\
\hline Total \% pH time $<4$ & - & $10.1(4.4-17.3)$ \\
\hline Upright \% pH time $<4$ & - & $9.2(1.7-20.7)$ \\
\hline Supine \% pH time $<4$ & - & $7.9(0.2-17.4)$ \\
\hline No. of reflux events & - & $79.0(48.2-104.3)$ \\
\hline No. of non-acid events & - & $18.0(5.0-36.5)$ \\
\hline No. of acid events & - & $39.0(30.0-66.0)$ \\
\hline No. of gas events & - & $7.5(1.8-22.8)$ \\
\hline LES length & - & $4.1(2.4-5.1)$ \\
\hline LES intraabdominal length & - & $1.5(1.0-3.2)$ \\
\hline LES end expiratory pressure & - & $17.0(12.0-25.4)$ \\
\hline DCI mmHg $\mathrm{s} \cdot \mathrm{cm}$ & - & $360(56-734)$ \\
\hline $\begin{array}{l}\text { No. of swallows }<\text { DCl } \\
\text { 450 mmHg } \cdot \mathrm{S} \cdot \mathrm{cm}\end{array}$ & - & $8(5-10)$ \\
\hline Ineffective esophageal motility & $25(67.6 \%)^{\mathrm{a}}$ & - \\
\hline $\begin{array}{l}\text { Values are median }(I Q R \text { interquartile range) unless indicated otherwise } \\
\text { LES lower esophageal sphincter, } D C / \text { distal contractile integral }\end{array}$ & \\
aValues in parentheses are percentages &
\end{tabular}

Table 3 Perioperative details

\begin{tabular}{|l|l|}
\hline & $n=37$ \\
\hline Operating time (minutes) & $55(41.4-70.3)^{\mathrm{a}}$ \\
\hline Hiatal hernia repair & $23(62.2)$ \\
\hline Postoperative dysphagia & 0 \\
\hline Hospital stay (days) & $2(2-2.5)^{\mathrm{a}}$ \\
\hline Previous foregut surgery & $6(15.8)$ \\
\hline Explantation of device & $6(15.8)$ \\
\hline $\begin{array}{l}\text { Values in parentheses are percentages unless indicated otherwise } \\
\text { aValues are median (IQR interquartile range) }\end{array}$
\end{tabular}

without causing side effects such as dysphagia, inability to belch, or bloating.

Electrical stimulation therapy of the lower esophageal sphincter was introduced following the idea of restoring the intrinsic competence of the LES through a chronic "training" of the sphincter. Encouraging research in animal models showed an increase in LES pressure during EST without affecting the swallow-induced LES relaxation and esophageal contractile activity $[7,16]$.

After successful studies in humans proving the increase of LES pressure during stimulation with temporarily placed electrodes, a Chilean research group initiated the first prospective open-label trial $[6,17]$.

The herewith presented results showed a significant improvement of the GERD HRQL score regarding the symptoms heartburn and regurgitation 2 years after surgery (41 [QR 21-49] to 8.50 [IQR 4.25-20.5], $p<0.001)$. These results are in good correlation with the 2-year results of the first prospective trial by Rodriguez et al. published in 2015 (23.5 [IQR 21-25.3] to 0 [IQR 0-3], <0.001) [18]. Unlike the study population of their open-label trial, our study cohort is more heterogeneous. Having read the promising results of LESEST in the literature, we believed that this novel technique might have a special place in the treatment of 


\section{GERD HRQL composite}

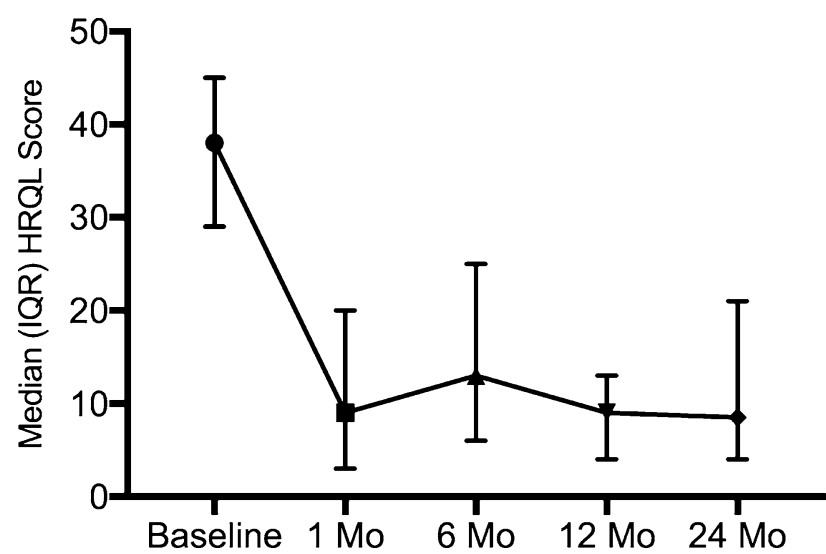

Fig. 3 Change in median (interquartile range, $I Q R$ ) gastroesophageal reflux disease (GERD) health-related quality of life (HRQL) composite score. $P<0.001$ versus baseline and 24month follow-up

\section{GERD HRQL regurgitation}

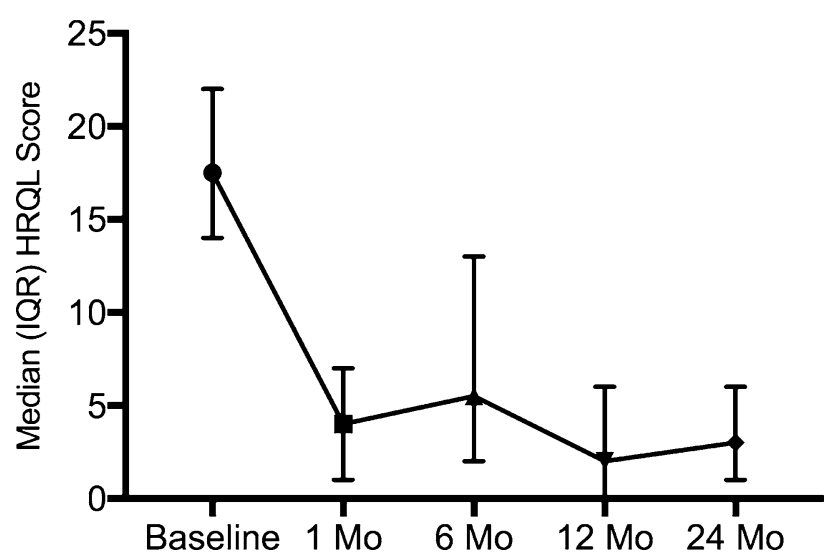

Fig. 5 Change in median (interquartile range, IQR) gastroesophageal reflux disease (GERD) health-related quality of life $(H R Q L)$ regurgitation score. $P<0.001$ versus baseline and 24month follow-up

challenging patients, such as patients with preceding failed anti-reflux procedures or patients with severe motility disorders.

In the subgroup of patients after redo foregut surgery, 2 out of 6 patients were off PPI 1 year after surgery and were satisfied regarding the present condition of heartburn and regurgitation during followup visits.

Moreover, we demonstrated in the patient subgroup of GERD and IEM that LES-EST improved GERD symptom control without jeopardizing swallowing function in the postoperative course [11].

However, in 4 patients we observed technical problems with the stimulation device, which eventually led to explantation of the EST device and conversion to fundoplication. The technical workup of the

\section{GERD HRQL heartburn}

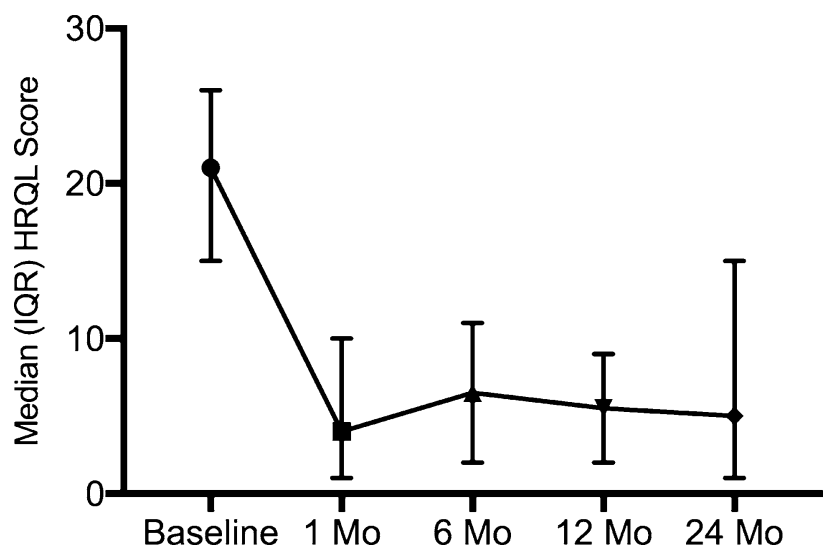

Fig. 4 Change in median (interquartile range, $I Q R$ ) gastroesophageal reflux disease (GERD) health-related quality of life (HRQL) heartburn score. $P<0.001$ versus baseline and 24month follow-up

explanted devices revealed leakage of the insulation sleeve of the cable as the cause of failure.

The explantation surgery itself was uneventful, without observing hostile adhesions or other challenging aspects. However, preparation process during lead explanation might lead to possible injury of the esophagus and should preferably be done by experienced surgical teams. The conversion to fundoplication itself did not resolve in adverse events and patients reported satisfying GERD symptom control.

The fact that $23.7 \%$ of the patients took PPI 1 year after surgery is comparable with recently published long-term results of a randomized controlled trial comparing Nissen fundoplication $(22 \%$ on PPI 10 years after surgery) with anterior partial fundoplication (39\% used PPI in the long-term follow-up) [19].

This study has some limitations that need to be stressed. First of all, this study was designed as an observational study assessing feasibility and safety. Therefore, the study population is fairly inhomogeneous. Therefore, the results cannot easily be generalized. Secondly, the number of treated patients is too low to perform a statistically sound subgroup analysis. For a more objective assessment of acid exposure, follow-up pH-metry is missing. To clarify this concern, the follow-up study including full esophageal functional testing is to be expected.

\section{Conclusion}

This study aimed to elucidate the clinical outcomes of LES-EST. We could demonstrate that LES-EST is safe and efficient. Still, the considerably high rate of device dysfunction should be alarming. Due to the low rate of GI side effects and its minimally invasive character preserving the anatomy of LES, this novel technique might find its place in anti-reflux surgery. 
Funding Open access funding provided by Medical University of Vienna.

Conflict of interest All authors meet the criteria for authorship as set forth in the Consensus Statement on Journal Authorship. M. Paireder, I. Kristo, M. Nikolic, G. Jomrich, J. Steindl, E. Rieder, R. Asari, and S.F. Schoppmann have no conflicts of interest or financial ties to disclose. The Upper GI Research Group at the Medical University of Vienna received research funding from the company EndoStim.

Open Access This article is licensed under a Creative Commons Attribution 4.0 International License, which permits use, sharing, adaptation, distribution and reproduction in any medium or format, as long as you give appropriate credit to the original author(s) and the source, provide a link to the Creative Commons licence, and indicate if changes were made. The images or other third party material in this article are included in the article's Creative Commons licence, unless indicated otherwise in a credit line to the material. If material is not included in the article's Creative Commons licence and your intended use is not permitted by statutory regulation or exceeds the permitted use, you will need to obtain permission directly from the copyright holder. To view a copy of this licence, visit http://creativecommons.org/licenses/by/4.0/.

\section{References}

1. El-Serag HB, Sweet S, Winchester CC, Dent J. Update on the epidemiology of gastro-oesophageal reflux disease: a systematic review. Gut. 2014;63(6):871-80.

2. GBD 2017 Gastro-oesophageal Reflux Disease Collaborators. The global, regional, and national burden of gastrooesophageal reflux disease in 195 countries and territories, 1990-2017: a systematic analysis for the Global Burden of Disease Study 2017. Lancet Gastroenterol Hepatol. 2020;5(6):561-81.

3. Chandrasoma P. New evidence defining the pathology and pathogenesis of lower esophageal sphincter damage. Eur Surg. 2019;51(6):282-90.

4. Vakil N, van Zanten SV, Kahrilas P, Dent J, Jones R, Global Consensus Group. The Montreal definition and classification of gastroesophageal reflux disease: a global evidencebased consensus. AmJGastroenterol. 2006;101(8):1900-20. quiz 1943.

5. Ellis F, Berne TV, Settevig K. The prevention of experimentally induced reflux by electrical stimulation of the distal esophagus. Am J Surg. 1968;115(4):482-7.

6. Rodríguez L, Rodríguez P, Neto MG, Ayala JC, Saba J, Berel D, et al. Short-term electrical stimulation of the lower esophageal sphincter increases sphincter pressure in patients with gastroesophageal reflux disease. Neurogastroenterol Motil. 2012;24(5):446-50.

7. KimSE, Soffer E. Electrical stimulation for gastroesophageal reflux disease: current state of the art. Clin Exp Gastroenterol. 2016;9:11-9.
8. Rodríguez L, Rodriguez P, Gómez B, Ayala JC, Saba J, PerezCastilla A, et al. Electrical stimulation therapy of the lower esophageal sphincter is successful in treating GERD: final results of open-label prospective trial. Surg Endosc. 2013;27(4):1083-92.

9. Rodríguez L, Rodriguez PA, Gómez B, Netto MG, Crowell MD, Soffer E. Electrical stimulation therapy of the lower esophageal sphincter is successful in treating GERD: longterm3-year results. SurgEndosc. 2016;30(7):2666-72.

10. Kappelle WFW, Bredenoord AJ, Conchillo JM, Ruurda JP, Bouvy ND, van Berge Henegouwen MI, et al. Electrical stimulation therapy of the lower oesophageal sphincter for refractory gastro-oesophageal reflux disease-interim results of an international multicentre trial. Aliment Pharmacol Ther. 2015;42(5):614-25.

11. Paireder M, Kristo I, Asari R, Jomrich G, Steindl J, Rieder E, et al. Electrical lower esophageal sphincter augmentation in patients with GERD and severe ineffective esophageal motility-a safety and efficacy study. Surg Endosc. 2019;33(11):3623-8.

12. Ciotola F, Ditaranto A, Bilder C, Badaloni A, Lowenstein D, Riganti JM, et al. Electrical stimulation to increase lower esophageal sphincter pressure after POEM. Surg Endosc. 2015;29(1):230-5.

13. Rieder E, Paireder M, Kristo I, Schwameis K, Schoppmann SF. Electrical stimulation of the lower esophageal sphincter to treat gastroesophageal reflux after POEM. Surg Innov. 2018;25(4):346-9.

14. Velanovich V. Comparison of generic (SF-36) vs. disease-specific (GERD-HRQL) quality-of-life scales for gastroesophageal reflux disease. J Gastrointest Surg. 1998;2(2):141-5.

15. Mellow MH, Pinkas H. Endoscopic therapy for esophageal carcinoma with Nd:YAG laser: prospective evaluation of efficacy, complications, and survival. Gastrointest Endosc. 1984;30(6):334-9.

16. Sanmiguel CP, Hagiike M, Mintchev MP, Cruz RD, Phillips EH, Cunneen SA, et al. Effect of electrical stimulation of the LES on LES pressure in a canine model. Am J Physiol Gastrointest Liver Physiol. 2008;295(2):G389-G94.

17. Banerjee R, Pratap N, Kalpala R, Reddy DN. Effect of electrical stimulation of the lower esophageal sphincter using endoscopically implanted temporary stimulation leads in patients with reflux disease. Surg Endosc. 2014;28(3):1003-9.

18. Rodríguez L, Rodriguez P, Gómez B, Ayala JC, Oxenberg D, Perez-Castilla A, et al. Two-year results of intermittent electrical stimulation of the lower esophageal sphincter treatment of gastroesophageal reflux disease. Surgery. 2015;157(3):556-67.

19. Hopkins RJ, Irvine T, Jamieson GG, Devitt PG, Watson DI. Long-term follow-up of two randomized trials comparing laparoscopic Nissen $360^{\circ}$ with anterior $90^{\circ}$ partial fundoplication. BrJ Surg. 2020;107(1):56-63.

Publisher's Note Springer Nature remains neutral with regard to jurisdictional claims in published maps and institutional affiliations. 